\title{
Fluoxetine, Desipramine, and the Dual Antidepressant Milnacipran Reduce Alcohol Self-Administration and/or Relapse in Dependent Rats
}

\author{
Emmanuelle Simon O'Brien', Rémi Legastelois', Hakim Houchi', Catherine Vilpoux', \\ Stéphanie Alaux-Cantin', Olivier Pierrefiche', Etienne André ${ }^{2}$ and Mickaël Naassila*,' \\ 'Equipe Région INSERM ERI 24, Groupe de Recherche sur l'Alcool et les Pharmacodépendances, Université de Picardie Jules Verne, Faculté de \\ Pharmacie, Amiens, France; ' 2 Laboratoires Pierre Fabre, Public Health, Castres, France
}

\begin{abstract}
A few clinical studies have shown that dual antidepressants (serotonergic (5-HT) and noradrenergic (NE) transporter inhibitors, SNRIs) may be effective in alcoholism treatment. We studied the effect of the dual antidepressant milnacipran on ethanol operant selfadministration in acutely withdrawn ethanol-dependent and in -non-dependent Wistar rats, and used fluoxetine and desipramine to dissect both 5-HT and NE components, respectively, in the effect of milnacipran. Milnacipran was also tested for relapse after protracted abstinence and on ethanol-induced $(1.0 \mathrm{~g} / \mathrm{kg})$ conditioned place preference in control rats and ethanol-induced locomotor sensitization in DBA $/ 2$ f female mice. Milnacipran dose dependently $(5-40 \mathrm{mg} / \mathrm{kg})$ attenuated the increased ethanol self-administration observed during early withdrawal and was more potent in preventing reinstatement in dependent rats after protracted abstinence as compared with nondependent rats. Desipramine and fluoxetine $(10 \mathrm{mg} / \mathrm{kg}$ ) blocked ethanol self-administration during early withdrawal, and recovery was delayed in dependent animals, indicating a potent effect. Ethanol self-administration was also reduced I day after treatment with desipramine and fluoxetine but not with milnacipran. Finally, milnacipran prevented ethanol-induced place preference in ethanol-naive rats and reduced the magnitude of ethanol-induced sensitization associated with a delayed induction in mice. Desipramine $(20 \mathrm{mg} / \mathrm{kg})$ countered sensitization development and reduced its expression at I week after treatment; fluoxetine $(10 \mathrm{mg} / \mathrm{kg})$ reduced sensitization expression. Thus, 5-HT and NE transmissions during sensitization expression may mediate the effect of milnacipran on sensitization induction. These results support that SNRIs may have a potential use in alcoholism treatment.

Neuropsychopharmacology (20I I) 36, I5 I8-1530; doi:I 0.1038/npp.20 I I.37; published online 23 March 20I I
\end{abstract}

Keywords: alcohol; addiction; antidepressant; operant self-administration; relapse; sensitization

\section{INTRODUCTION}

Alcoholism is a devastating illness with a profound public health impact. The efficacy of current pharmacotherapies is modest and limited by patient non-adherence to treatment and disease heterogeneity. Alcoholism and depression comorbidity has been extensively documented and may be based on common neurobiological factors involving both serotonergic (5-HT) and noradrenergic (NE) pathophysiological mechanisms (Markou et al, 1998). Activation of the 5-HT system decreases ethanol intake while lower levels of 5-HT have been measured in alcohol-dependent subjects (LeMarquand et al, 1994). A previous study has shown that inhibitors of $\mathrm{NE}$ and/or 5-HT uptake decrease alcohol

*Correspondence: Professor M Naassila, Equipe Région INSERM ERI 24, Groupe de Recherche sur l'Alcool et les Pharmacodépendances, Université de Picardie Jules Verne, Faculté de Pharmacie, I rue des Louvels, Amiens 80000, France, Tel: + 333228277 58, Fax: + 333228276 72, E-mail: mickael.naassila@u-picardie.fr Received 16 February 2011; accepted 23 February 2011 intake in alcohol-preferring rats (Daoust et al, 1984). Hwang et al (2000) reported a downregulation of NE transporter (NET) in the locus coeruleus of alcohol-preferring rats that may be associated with alcohol-seeking behavior.

Alcohol-dependent subjects also display reduced 5-HT transporter (5-HTT) density, which in turn may affect anxiety and depression, increasing the risk of relapse (Heinz et al, 1998). Results obtained with 5-HTT inhibitor in alcohol-dependent patients are mixed. These mixed results may be explained by the sub-type of alcohol-dependent patient who is treated and by the fact that alcohol intake is concurrently regulated by interactions of multiple neurotransmitter systems (Kenna, 2010; Pettinati, 2001). The ability to modify the levels of multiple monoamine neurotransmitters may be the key to treating alcoholism in a broader population. Of interest, a triple monoamine neurotransmitter uptake inhibitor (NE, 5-HT, and dopamine) DOV 102 677, has been shown to decrease voluntary ethanol intake in an ethanol-preferring rat strain (McMillen et al, 2007). 
Mirtazapine (a 5-HT and NET inhibitor, SNRI) reduces the severity of anxiety and depressive symptoms during alcohol detoxification (Liappas et al, 2005), suggesting that it may facilitate alcohol dependence treatment during its initial phase. There is also evidence in alcohol-dependent patients with depressive disorders that mirtazapine improves mood and reduces alcohol craving (Yoon et al, 2006).

Milnacipran, an equipotent inhibitor of both 5-HTT and $\mathrm{NET}$, is a commonly used antidepressant that has also shown efficacy by improving chronic pain disorders (Owen, 2008). Because depression and alcoholism share common mechanisms that imply the involvement of both the 5-HT and NE pathways (Markou et al, 1998), we hypothesized that milnacipran could be efficient in reducing alcoholinduced behaviors and could provide a new treatment for alcohol addiction.

We also hypothesized that milnacipran could interfere with the development of ethanol-induced locomotor sensitization, that is an important component in alcohol addiction. To test our hypotheses, we used chronic and intermittent ethanol vapor exposure protocols in rats (Gilpin et al, 2008; Naassila et al, 2000). Rats exposed to this protocol display enhanced anxiety and excessive ethanol self-administration during withdrawal (O'Dell et al, 2004; Valdez et al, 2002). This model of alcohol dependence induction allowed us to test the efficacy of a pharmacological treatment on motivation to drink alcohol associated with dependence and relapse. Motivation for drinking alcohol was measured using an ethanol operant self-administration paradigm. We evaluated the efficacy of milnacipran on operant self-administration during acute withdrawal and during relapse after a protracted period of abstinence. We finally tested in non-dependent rats the effect of this compound on ethanol reinforcement and on the conditioned motivational properties of ethanol using a conditioned place preference (CPP) paradigm (Barbier et al, 2008). In addition, repeated ethanol exposure induces sensitization of $\mathrm{NE}$ and 5-HT neurons (Lanteri et al, 2008); thus, we investigated the effect of milnacipran on ethanol-induced behavioral sensitization, that is defined as a long-lasting and progressive enhancement of the locomotor and motivational responses to ethanol after repeated and intermittent administration (Kalivas and Stewart, 1991). This sensitization is suggested to be analogous to characteristic behaviors of drug addiction (Robinson and Berridge, 1993).

To dissociate both 5-HT and NE components in the effects of milnacipran, we tested fluoxetine (5-HTT inhibitor) and desipramine (NET inhibitor) on excessive motivation for ethanol during acute withdrawal and on ethanol-induced behavioral sensitization.

\section{MATERIALS AND METHODS}

\section{Animals}

Male Wistar rats weighing 200-250g on arrival in our animal care unit were obtained from Charles River Laboratory (L'Arbresle, France). Animals were housed four per cage, and lights were on a reversed 12-h light/dark cycle (lights on at 1900 hours) in a temperature-controlled $\left(21 \pm 0.5^{\circ} \mathrm{C}\right)$ and humidity-controlled $(55 \pm 10 \%)$ environment, with food and water available ad libitum (except for a week of forced-ethanol exposure $(10 \% \mathrm{v} / \mathrm{v})$ before the selfadministration procedure).

Female DBA/2J mice, a strain chosen for its sensitivity to the stimulatory and sensitizing effects of ethanol (Phillips et al, 1995) were purchased from Janvier (Le Genest Saint Isle, France). Females were used because they tend to develop more robust sensitization than males (Forgie and Stewart, 1994; Robinson, 1984). Mice were housed 10 per cage and acclimated to the colony room for at least 10 days. At the beginning of the experiments, mice were 8-9 weeks old and weighed $20 \pm 2 \mathrm{~g}$.

The number of animals was kept to a minimum, and all efforts were made to avoid animal suffering. Experiments were carried out in strict accordance with both the guidelines for Care and Use of Laboratory Animals (NIH) and the European Community regulations for animal use in research (CEE No 86/609) and were also approved by the local ethics committee.

\section{Drugs}

Ethanol (VWR, Strasbourg, France) and sucrose (Sigma Aldrich, Saint Quentin Fallavier, France) solutions were prepared in tap water. Milnacipran (cis-2-aminomethyl$N, N$-diethyl-1-phenylcyclopropanecarboxamide monohydrochloride) was obtained from Pierre Fabre (Gaillac, France). The range of doses of milnacipran $(5,10,20$, and $40 \mathrm{mg} / \mathrm{kg}$ ) was chosen because they do not have locomotor effects (Mochizuki et al, 2002). Milnacipran treatment was administered intraperitoneally (i.p.) $20 \mathrm{~min}$ before experiments. Extracellular levels of 5-HT and NE are increased $20 \mathrm{~min}$ after an i.p. injection of $30 \mathrm{mg} / \mathrm{kg}$ of milnacipran (Tachibana et al, 2004). Desipramine (Sigma-Aldrich, France) was administered i.p. an hour before experiments as was fluoxetine (Tocris, Bristol, United Kingdom) (Tanda et al, 1996). For i.p. injections, all compounds and ethanol were dissolved in saline, and injection volumes were $1 \mathrm{ml}$ per $200 \mathrm{~g}$ body weight and $1.25 \mathrm{ml}$ per $100 \mathrm{~g}$ body weight for rats and mice, respectively. Control animals were treated with saline injections.

\section{Ethanol Operant Self-Administration}

These experiments were carried out in standard operant chambers (Bioseb, Vitrolles, France) installed in soundattenuated and ventilated cubicles. The chambers were connected to a computer running PackWin software to record activity. The left side of each chamber contained two levers located below a stimulus light and on either side of the drinking cup. Animals were trained 5 days a week in 30min sessions for 10 weeks to self-administer a solution of $10 \%$ ethanol using a sucrose fading procedure (Samson, 1986). A $0.1 \mathrm{ml}$ drop of $10 \%$ ethanol was delivered after each active lever response (fixed ratio, 1). Each reinforcer was followed by a 3-s time-out period during which additional active lever presses did not result in reinforcer delivery. Each active lever press was associated with a light cue that was also used during the reacquisition procedure.

For the first 3 days of training, rats had limited access to water $3 \mathrm{~h}$ per day. Self-administration training started the 
first day with a free delivery of $10 \%$ sucrose every minute to shape the approach to the central receptacle. On days 2-6, rats received no free deliveries of sucrose, but presses on any lever produced a mixed $10 \%$ sucrose- $10 \%$ ethanol delivery. Starting on day 7 , only one active lever resulted in a delivery of the $10 \%$ sucrose- $10 \%$ ethanol reinforcer. The active lever was then alternated between left and right during five sessions to minimize potential positional biases. The sucrose fading procedure then began on day 12 , ie, sucrose concentration was gradually decreased while ethanol concentration was maintained at $10 \%$. Starting at day 24 , rats were allowed to respond for $10 \%$ ethanol for 5 weeks to stabilize operant behavior.

\section{Ethanol Vapor Inhalation}

Rats were housed individually in standard cages, had unlimited access to water and food, and were exposed to ethanol vapor in sealed clear plastic chambers (550l) (Naassila et al, 2000). Ethanol vapor was generated by introducing pressured air into a $96 \%$ ethanol reservoir (60-80\% of hygrometry). Ethanol vapor concentration was gradually increased for 3 weeks to reach stable blood ethanol concentrations (BECs; between 150 and $250 \mathrm{mg} / \mathrm{dl}$ ). Ethanol was evaporated for $14 \mathrm{~h}$ each day (on 1900; off 0900 hours; O'Dell et al, 2004) for 10 weeks (Rimondini et al, 2002). BECs were regularly determined to permit the adjustment of ethanol vapor concentrations using an Analox AM1 Instrument analyzer (Imlab, Lille, France). Rats subjected to this chronic ethanol vapor inhalation showing a physical dependence, shown by the appearance of somatic withdrawal signs, as previously described (O'Dell et al, 2004; Roberts et al, 2000). During the same period, control (non-dependent) animals were placed in a separate sealed plastic chamber and exposed to a continuous flow of air.

\section{Experimental Procedure}

At the end of the 10-week period of dependence induction, rats $(n=12)$ were re-tested for $10 \%$ ethanol self-administration following a 6 -h withdrawal period from ethanol vapors. At this time point, BECs returned to 0 , and dependent rats were expected to show a significant increase in ethanol lever pressing, as previously described (Rimondini et al, 2002). As soon as dependent and nondependent animals showed a stable baseline, each rat received 0 (saline), $5,10,20$, or $40 \mathrm{mg} / \mathrm{kg}$ milnacipran in a Latin square counterbalanced design (Gehlert et al, 2007). Two other groups of rats received either desipramine or fluoxetine at $10 \mathrm{mg} / \mathrm{kg}$.

In another experiment, we investigated whether the effect of milnacipran on operant self-administration was specific to ethanol by measuring its effects on the reinforcing effects of sucrose, a natural rewarding substance. The $2 \%$ sucrose concentration was chosen to achieve the same level of response as that observed in dependent rats self-administering $10 \%$ ethanol (about 100 deliveries). Eight nondependent rats were trained for sucrose self-administration under a FR1 schedule using $0.1 \mathrm{ml}$ of a $2 \%$ sucrose solution as the reinforcer. Rats were trained 5 days a week in 30-min sessions. Once animals showed a stable baseline, different doses of milnacipran $(5,10,20$, and $40 \mathrm{mg} / \mathrm{kg})$ were tested.

\section{Extinction of Ethanol-reinforced Responding}

At 1 week after removal from the vapor chambers, ethanolreinforced responding was extinguished in daily 30-min sessions. Lever responses were counted, but no programmed events occurred (no ethanol delivery and no light cue). Daily sessions continued until all rats $(n=12$ for dependent group; $n=8$ for non-dependent controls) reached an extinction criterion of fewer than six responses per session for 3 consecutive days.

\section{Reacquisition Testing}

After 2 weeks of extinction, rats were injected with milnacipran ( 10 or $40 \mathrm{mg} / \mathrm{kg}$ ) or saline $20 \mathrm{~min}$ before testing reacquisition. To trigger memory retrieval of operant responding for ethanol, the light cue (CS) and two primes of ethanol $(0.1 \mathrm{ml}$ of $10 \%$ ethanol, spaced by $1 \mathrm{~min})$ were delivered at the beginning of the test session. Then, each press on the active lever resulted in the delivery of $0.1 \mathrm{ml}$ of $10 \%$ ethanol during the entire self-administration session (30 min; Carnicella et al, 2009; Peana et al, 2009).

\section{Ethanol-induced CPP in Wistar Rats}

We used a two-chamber apparatus (Bioseb, Chaville, France), consisting of two $20 \times 40 \times 40 \mathrm{~cm}$ compartments with distinct visual and tactile cues, as previously described (Barbier et al, 2008). The two compartments were separated by a guillotine door. Distance and time spent in each compartment were measured by computer-interfaced infrared photobeams $(16 \times 16)$. Both compartments were illuminated by dim light with 40 lux brightness. The procedure consisted of three phases: preconditioning (day 1), conditioning (days 2-5), and post conditioning (day 6). To control for possible innate preferences for one of the two compartments, rats underwent a single preconditioning session. Immediately after saline injection, they were allowed free access to both conditioning compartments for $15 \mathrm{~min}$. Rats ( $n=10$ per group) were randomly assigned to undergo either drug conditioning in the morning and saline conditioning in the afternoon, or vice versa. Rats received a total of two injections per day.

For drug conditioning, rats were randomly assigned to receive either saline or ethanol $(1.0 \mathrm{~g} / \mathrm{kg}$, prepared at $20 \%$ $\mathrm{v} / \mathrm{v}$ in saline). At $10 \mathrm{~min}$ following administration, animals were confined to one of the two compartments for $15 \mathrm{~min}$. The drug- and saline-paired conditioning compartments and the time of the drug or saline conditioning session (morning or afternoon) were counterbalanced across all groups. Conditioning sessions were conducted twice daily for 4 days, with a minimum of $5 \mathrm{~h}$ between conditioning sessions. On the day following the last conditioning session, we tested animals for CPP by placing them between the two compartments (guillotine door removed) and allowing them free access to both conditioning compartments for $15 \mathrm{~min}$. CPP was determined by comparing the time spent in the drug-paired compartment during the preconditioning session and the time spent in the 
drug-paired compartment during the test session. The total number of entries into each compartment and the total distance traveled were measured during both preconditioning and test sessions. Milnacipran (10 or $40 \mathrm{mg} / \mathrm{kg}$ ) or saline was administered $10 \mathrm{~min}$ before each ethanol injection. Milnacipran $(40 \mathrm{mg} / \mathrm{kg})$ alone was also tested as the conditioning drug.

\section{Ethanol-Induced Locomotor Sensitization in Female DBA/2J Mice}

Locomotor activity was assessed using the LE 8811 IR motor activity monitor (Bioseb, Chaville, France). Mice were placed in a $40 \times 40 \mathrm{~cm}$ open field with opaque acrylic walls. The chamber was transected with infrared photocell beams $2 \mathrm{~cm}$ above the floor at 16 sites along each side. Test chambers were shielded from external noise and illuminated with indirect white light (20lux). Horizontal locomotion was measured from photocell beam interruptions using ActiTrack software. The general sensitization procedure was similar to that used by Pastor and Aragon (2006). On the first day of the experiment (habituation day), all mice were weighed, injected with saline solution $(12.5 \mathrm{ml} / \mathrm{kg})$, and immediately placed into the open field. Locomotor activity was recorded for the next $5 \mathrm{~min}$. Mice were then divided into several groups that were equated in terms of horizontal locomotion. The next day, the sensitization procedure started. Every day, mice were injected with milnacipran 10 or $40 \mathrm{mg} / \mathrm{kg}$ (Mil10 or Mil40), desipramine 10 or $20 \mathrm{mg} / \mathrm{kg}$ (D10 or D20), fluoxetine 5 or $10 \mathrm{mg} / \mathrm{kg}$ (F5 or F10), or saline solution, followed by an injection of ethanol $2.0 \mathrm{~g} / \mathrm{kg}$ or saline solution $20 \mathrm{~min}$ (milnacipran) or $60 \mathrm{~min}$ (desipramine and fluoxetine) later and were immediately placed in the open field. Each mouse received a total of two injections per day. Locomotor activity was recorded for $5 \mathrm{~min}$ to capture the stimulant effects of the ascending limb of the blood alcohol concentrations (Didone et al, 2008). These daily treatments were conducted for 10 days (day 1 to 10). After the 10th day, mice were left undisturbed in their home cages for 7 days. All mice received a single injection of ethanol $2.0 \mathrm{~g} / \mathrm{kg}$ on day 17 (ethanol challenge) and saline on day 18 (saline challenge) immediately before locomotor activity testing.

\section{Effect of Acute Milnacipran on Locomotor Activity in Ethanol-sensitized Mice}

We used mice from a saline/ethanol group. On day 30 (11 days after the saline challenge), mice received an acute ethanol injection $(2.0 \mathrm{~g} / \mathrm{kg})$ immediately before a 5-min locomotor activity test. The next day, they received an injection of milnacipran $(40 \mathrm{mg} / \mathrm{kg}) 20 \mathrm{~min}$ before ethanol injection and immediately underwent a 5-min locomotor activity test.

\section{Statistical Analysis}

Data are expressed as mean \pm SEM, and analyses were conducted using SigmaStat2.0 software. Data were submitted to a square root transformation to meet the requirements of homogeneity of variance if necessary. For the self-administration experiments, data were subjected to two-way analysis of variance (ANOVA) with repeated measure (RM; ethanol vapor $v s$ air control $\times$ treatments). Sucrose self-administration results were analyzed with a one-way RM-ANOVA. CPP experiments were also analyzed with two-way RM-ANOVA (treatments $\times$ session), as were data from the sensitization experiment (group $\times$ day). Post hoc comparisons were conducted using Tukey's test. Statistical significance was set at $P<0.05$.

\section{RESULTS}

\section{Ethanol Operant Self-administration in Dependent and Non-Dependent Rats}

Effect of milnacipran. As expected, rats exposed to ethanol vapor inhalation responded three times more for $10 \%$ ethanol self-administration than non-dependent rats $(\mathrm{F}(1,20)=15.619, P<0.001 ; 104$ vs 36 deliveries corresponding to $0.93 \pm 0.11 \mathrm{~g} / \mathrm{kg}$ and $0.3 \pm 0.05 \mathrm{~g} / \mathrm{kg}$, respectively, $P<0.001$; Figure 1a). ANOVA revealed a significant effect of milnacipran dose $(\mathrm{F}(4,80)=23.013, P<0.001)$ and a significant interaction between ethanol exposure and milnacipran dose $(\mathrm{F}(4,80)=2.845, P=0.029)$. A robust, dose-dependent suppression of ethanol self-administration by milnacipran was found. Post hoc analysis revealed a significant reduction in ethanol self-administration in dependent animals at the $10 \mathrm{mg} / \mathrm{kg}(P<0.05), 20 \mathrm{mg} / \mathrm{kg}$ $(P<0.01)$, and $40 \mathrm{mg} / \mathrm{kg}(P<0.001)$ doses of milnacipran compared with the saline injection. In contrast, milnacipran was less effective in altering ethanol self-administration in non-dependent animals. Only the highest dose of milnacipran significantly decreased lever presses $(P<0.05$ compared with 0 , ie, saline). Responses on the non-active lever were not affected in any of the groups (data not shown).

The day after milnacipran $(40 \mathrm{mg} / \mathrm{kg})$, rats showed the same level of response as compared with baseline, indicating a recovery $(P=0.004$ compared with $40 \mathrm{mg} / \mathrm{kg}$; Figure 1b).

Effect of desipramine. In another group of rats, desipramine $(10 \mathrm{mg} / \mathrm{kg})$ was tested in ethanol operant self-administration in dependent and non-dependent animals. A two-way ANOVA showed a significant effect of desipramine treatment $(\mathrm{F}(2,25)=15.465, P<0.001)$ and a significant interaction between ethanol exposure and treatment $(\mathrm{F}(2,25)=5.862, P=0.008)$. Post hoc analysis showed that dependent animals pressed for $10 \%$ ethanol significantly more than non-dependent animals $(P=0.039)$. This analysis also showed a significant reduction in ethanol self-administration in dependent animals as well as nondependent ones after desipramine $(P<0.001$ and $P=0.022$, respectively). Of interest, the day after desipramine injection, we observed that recovery was well established in nondependent rats $(P=0.002)$, whereas it was not achieved in dependent rats $(P=0.640$; Figure 2$)$, thus demonstrating that dependent animals were more sensitive to a single desipramine injection.

Effect of fluoxetine. Fluoxetine $(10 \mathrm{mg} / \mathrm{kg})$ was also tested in ethanol operant self-administration in both groups of animals. A two-way ANOVA showed a significant effect of fluoxetine $(\mathrm{F}(2,36)=26.592, P<0.001)$ and a significant 

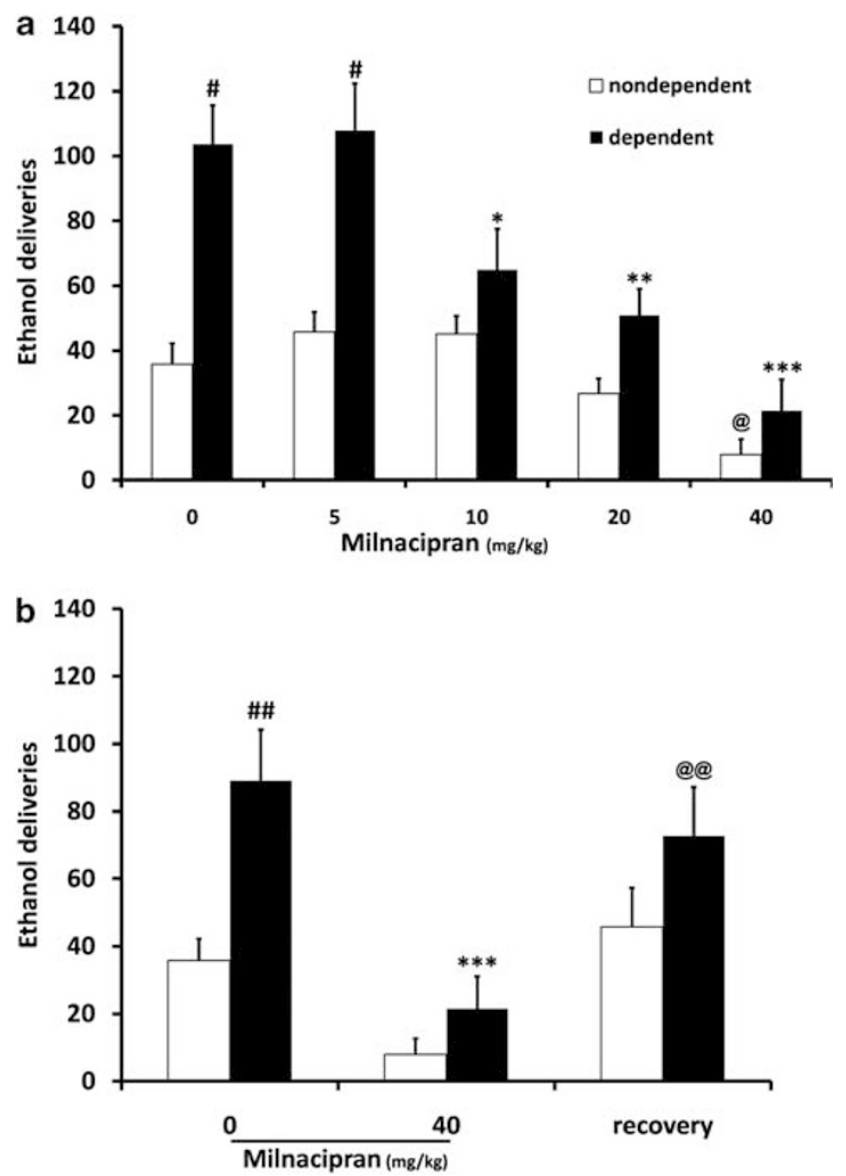

Figure I (a) Milnacipran dose dependently reduces ethanol selfadministration (number of ethanol deliveries) more efficiently in dependent rats compared with non-dependent rats. Ethanol dependence was induced by intermittent exposure to ethanol vapors for at least 10 weeks, and animals were then tested for ethanol self-administration after $6 \mathrm{~h}$ of acute withdrawal. Dependent rats $(n=12)$ showed a significant increase in the number of ethanol deliveries compared with non-dependent rats $(n=10)$. Milnacipran (i.p., $20 \mathrm{~min}$ before self-administration) significantly reduced ethanol self-administration in dependent animals, in a dose-dependent manner. In non-dependent rats, a significant effect was observed only at the highest dose. Values represent mean \pm SEM. ${ }^{\#} P<0.001$ compared with the same milnacipran dose in non-dependent animals. $* * * * P<0.00$ l, $* * P<0.0$ l, and $* P<0.05$ compared with saline treatment in dependent animals. ${ }^{@} P<0.05$ one-way ANOVA with repeated measures compared with 0 . (b) The day after milnacipran treatment $(40 \mathrm{mg} / \mathrm{kg})$, dependent and nondependent rats showed the same level of response as compared with baseline. ${ }^{\#} P<0.01$ compared with non-dependent rats, ${ }^{* * *} P<0.00$ I compared with 0 within dependent rats, and ${ }^{@} P<0.0$ l compared with milnacipran $40 \mathrm{mg} / \mathrm{kg}$ within dependent animals.

interaction between vapor exposure and fluoxetine $(\mathrm{F}(2,36=5.791, P=0.007)$. Post hoc analysis showed that dependent animals pressed more for $10 \%$ ethanol than nondependent animals $(P=0.006)$. Tukey's test also showed a significant reduction in lever presses for both groups after treatment with fluoxetine $(P<0.001)$. As for desipramine, recovery of ethanol self-administration was not achieved the day after fluoxetine injection in dependent rats $(P=0.895)$ compared with non-dependent rats $(P=0.01$; Figure 3$)$, demonstrating that dependent animals were more sensitive to a single fluoxetine injection.

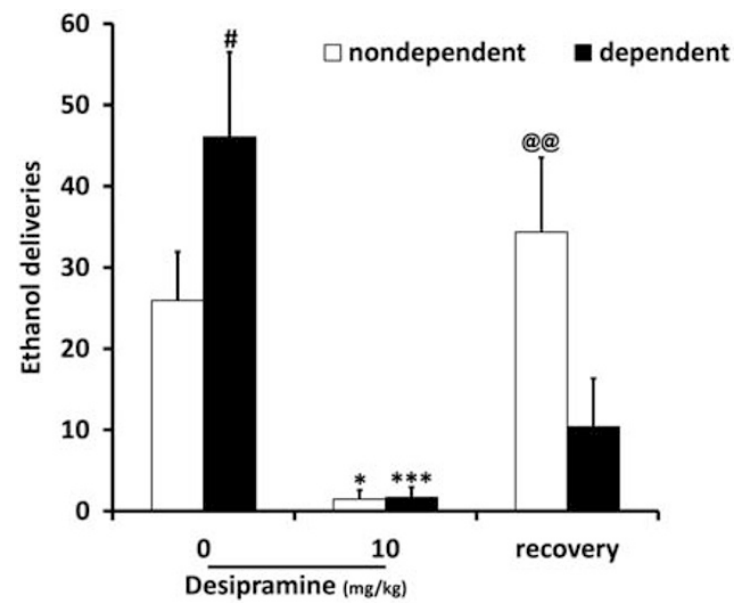

Figure 2 Desipramine $(10 \mathrm{mg} / \mathrm{kg})$ reduces ethanol self-administration in dependent $(n=6)$ and non-dependent $(n=8)$ rats. Values represent mean \pm SEM. ${ }^{\#} P<0.05$ compared with non-dependent rats. $* * * P<0.00$ I, $* P<0.05$ compared with 0 in both groups. ${ }^{@} P<0.01$ compared with desipramine treatment in non-dependent animals.

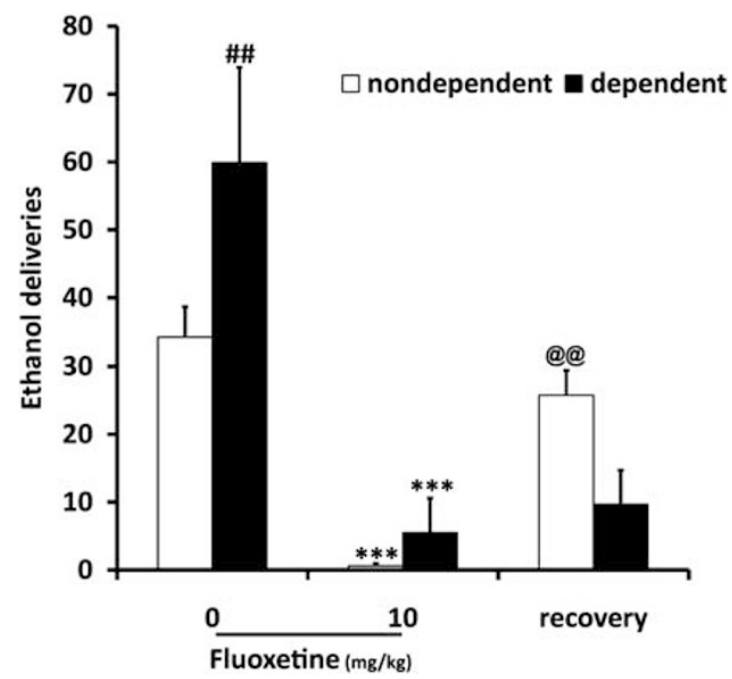

Figure 3 Fluoxetine $(10 \mathrm{mg} / \mathrm{kg})$ reduces ethanol self-administration in dependent $(n=6)$ and non-dependent $(n=8)$ rats. Values represent mean \pm SEM. ${ }^{\#} P<0.0$ I compared with non-dependent rats. ${ }^{* * *} P<0.00$ I compared with 0 in both groups. $@ @ p<0.01$ compared with fluoxetine treatment in non-dependent animals.

\section{Sucrose Operant Self-Administration}

One-way ANOVA showed a significant effect of milnacipran on sucrose self-administration $(\mathrm{F}(4,26)=10.106, P<0.001)$. Post hoc analysis revealed a significant reduction of sucrose self-administration in animals for the 20 and $40 \mathrm{mg} / \mathrm{kg}$ $(P<0.001)$ doses of milnacipran (Figure 4$)$.

\section{Reacquisition of Ethanol Self-Administration}

We examined the effect of milnacipran (10 and $40 \mathrm{mg} / \mathrm{kg}$ ) on operant response for ethanol in both control rats and rats with a history of dependence after a period of extinction. At the lowest dose $(10 \mathrm{mg} / \mathrm{kg})$, a two-way ANOVA showed a significant effect of milnacipran 


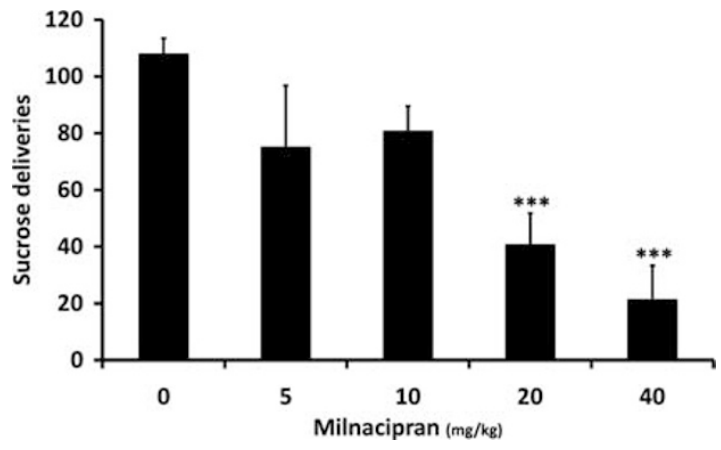

Figure 4 In non-dependent rats $(n=8)$, milnacipran reduces $2 \%$ sucrose self-administration starting at the $20 \mathrm{mg} / \mathrm{kg}$ dose. Values represent mean $\pm \mathrm{SEM}$. $* * * * P 0.00$ I compared with saline treatment.

$(\mathrm{F}(2,22)=28.799, P<0.001)$ and a significant interaction between ethanol vapor exposure and milnacipran $(\mathrm{F}(2,22)=3.987, P=0.33$; Figure 5a). Post hoc analysis revealed a strong reacquisition of ethanol self-administration for both dependent and non-dependent groups $(P=0.003$ and $P=0.001$, respectively). After treatment with $10 \mathrm{mg} / \mathrm{kg}$ before reacquisition, only the dependent group showed a significant decrease in ethanol self-administration $(P=0.034)$ compared with non-dependent rats, demonstrating that dependent animals were more sensitive to the anti-relapse effect of milnacipran.

For the $40 \mathrm{mg} / \mathrm{kg}$ dose, ANOVA showed a significant effect of milnacipran $(\mathrm{F}(2,36)=23.221, \quad P<0.001)$. As Figure $5 b$ indicates, a strong reacquisition of ethanol self-administration was observed in the control salineinjected rats, for both dependent and non-dependent groups $(P<0.001)$. This increase was selective for the lever associated with ethanol, wheras the response on the inactive lever remained very low $(0.5 \pm 0.23$ for dependent rats; $1 \pm 0.38$ for non-dependent rats, data not shown). The reacquisition of responding for ethanol was completely prevented in rats pretreated with milnacipran $(P<0.001$ compared with saline treatment) for both groups (10/12 rats were completely devoid of any response at the lever in the dependent group and $8 / 8$ in the nondependent group). These results demonstrate that milnacipran prevented relapse similarly in both groups at this high dose.

\section{Ethanol (1.0 g/kg)-Induced CPP}

When used as the conditioning drug, milnacipran $40 \mathrm{mg} / \mathrm{kg}$ alone failed to produce a CPP or aversion, indicating a lack of intrinsic rewarding or aversive effects of this compound (Figure 6). After pretreatment with milnacipran (10 or $40 \mathrm{mg} / \mathrm{kg}$ ), a dose-dependent reduction of ethanol place preference was observed (main effects of treatments $(\mathrm{F}(3,36)=5.365, P=0.004)$ and session $(\mathrm{F}(1,36)=19.783$, $P<0.001)$ and a significant interaction $(\mathrm{F}(3,36)=6.915$, $P<0.001))$. Post hoc analysis showed a significant ethanol place preference $(P<0.001)$ that was not altered at the dose of $10 \mathrm{mg} / \mathrm{kg}$ of milnacipran but that was significantly reduced at $40 \mathrm{mg} / \mathrm{kg}$ dose $(P<0.001$ compared with saline and $P<0.01$ compared with $10 \mathrm{mg} / \mathrm{kg}$ ).
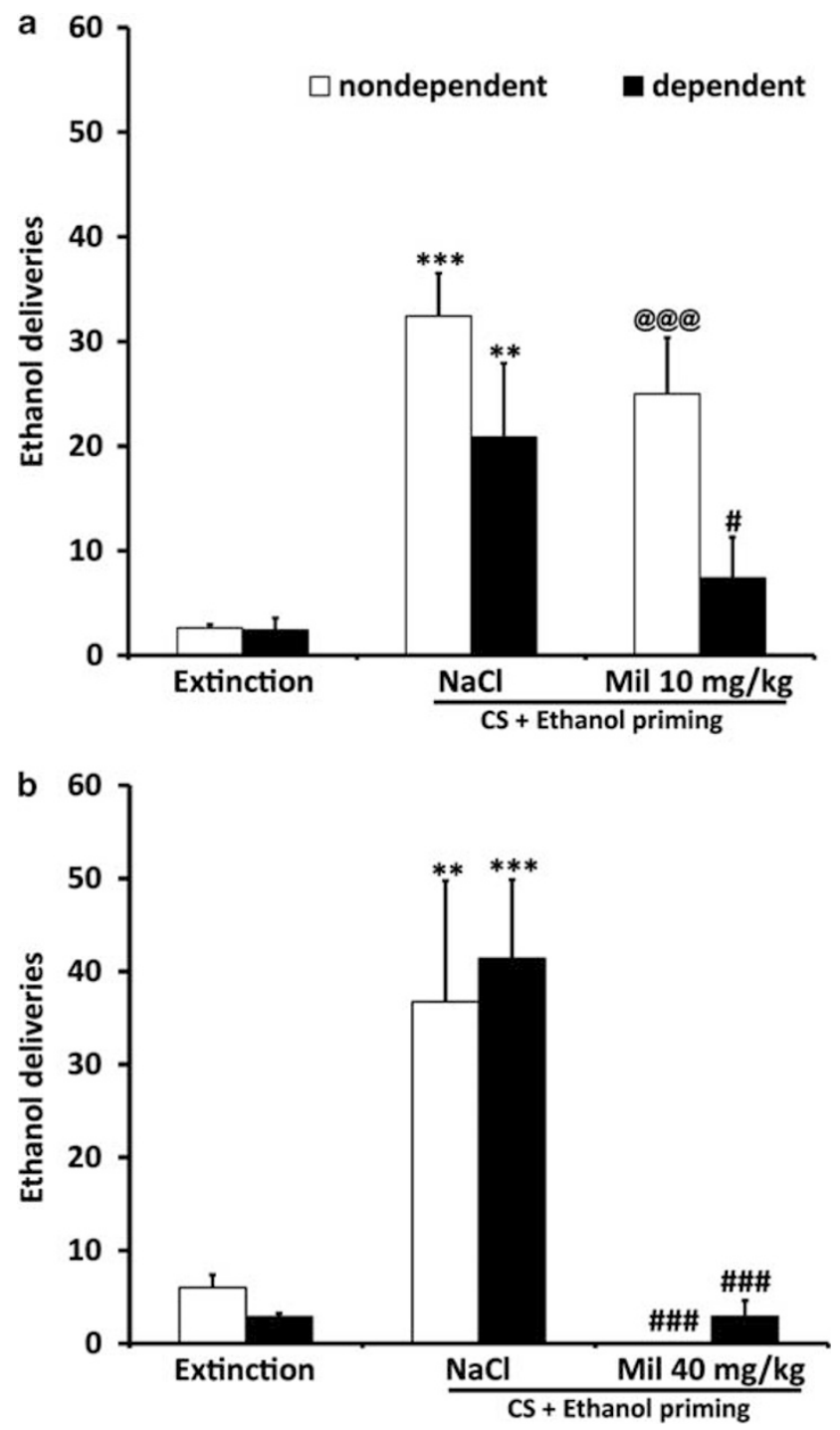

Figure 5 (a) Milnacipran $(10 \mathrm{mg} / \mathrm{kg})$ prevents ethanol self-administration reacquisition in dependent $(n=8)$ rats but not in non-dependent rats $(n=8)$. Extinction, responses during the final three extinction sessions; CS + ethanol priming, responses during presentation of an ethanolassociated conditioned stimulus. ${ }^{*} * P<0.01$ and $* * * P<0.001$ compared with respective extinction sessions; ${ }^{@ @} P<0.00$ I compared with extinction; ${ }^{\#} P<0.05$ compared with respective saline treatment. (b) Milnacipran $(40 \mathrm{mg} / \mathrm{kg})$ prevented ethanol self-administration reacquisition in dependent $(n=12)$ and non-dependent $(n=8)$ rats. $* * P<0.01$ and $* * * P<0.00$ I compared with respective extinction sessions; ${ }^{\# \#} P<0.00$ I compared with respective saline treatment.

\section{Ethanol-Induced Behavioral Sensitization}

The three following experiments were performed in two stages. The milnacipran experiment was completed first, with its own saline/saline and saline/ethanol groups. Then, both desipramine and fluoxetine experiments (the second and third experiments, respectively) were conducted simultaneously using common saline/saline and saline/ ethanol groups.

For the first analysis of each of the experiments, we considered only data from the 10 days of sensitization induction (days 1-10; Figure 7a-c). ANOVA showed a significant effect of group $(\mathrm{F}(4,42)=36.647 ; P<0.001)$ and 


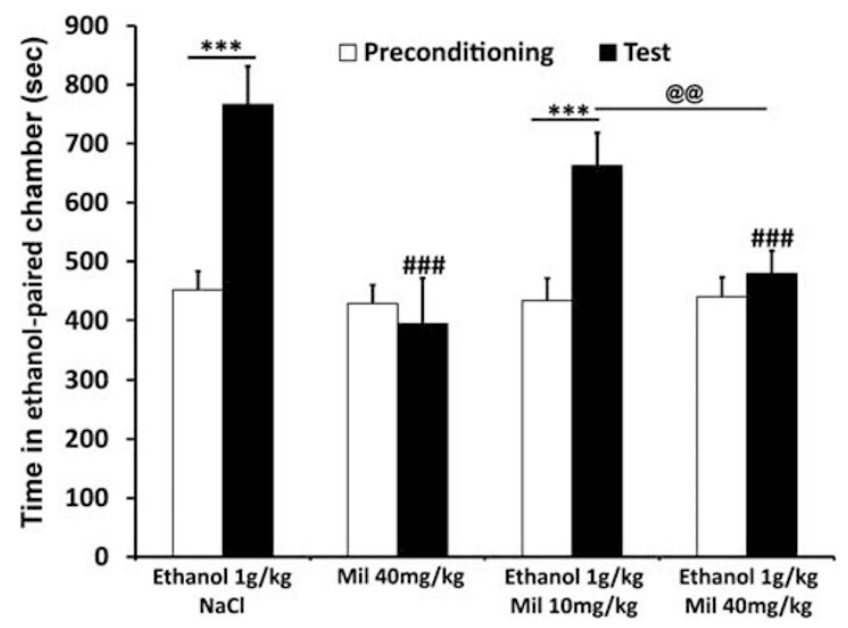

Figure 6 Milnacipran prevents ethanol $(1.0 \mathrm{~g} / \mathrm{kg})$-induced CPP in nondependent rats. Milnacipran (i.p., 20 min before the test and 10 min before ethanol injection) significantly reduced ethanol-induced CPP. Values represent mean \pm SEM. $* * * * P<0.00$ I compared with respective preconditioning session. ${ }^{\# \# \#} P<0.001$ and ${ }^{\#} P<0.05$, compared with the value of the saline ( $\mathrm{NaCl} 0.9 \%)$ group during the test session. ${ }^{@} P<0.0$ l compared with respective group of the $10 \mathrm{mg} / \mathrm{kg}$ dose.

day $(\mathrm{F}(9,375)=13.186 ; P<0.001)$ and a significant interaction $(\mathrm{F}(36,375)=4.975 ; P<0.001)$ in the first experiment (milnacipran, Figure 7a); a significant effect of group $(\mathrm{F}(5,55)=28.151 ; P<0.001)$ and day $(\mathrm{F}(9,489)=7.549$; $P<0.001)$ and a significant interaction $(\mathrm{F}(45,489)=6.347$; $P<0.001$ ) in the second experiment (desipramine, Figure 7b); and a significant effect of group $(\mathrm{F}(5,54)=60.397 ; P<0.001)$ and day $(\mathrm{F}(9,485)=21.095$; $P<0.001)$ and a significant interaction $(\mathrm{F}(45,485)=8.975$; $P<0.001)$ in the third experiment (fluoxetine, Figure $7 \mathrm{c}$ ). Post hoc analysis revealed that a daily injection of milnacipran, desipramine, or fluoxetine did not change basal locomotor activity compared with controls (Mil40/ saline, D10/saline, D20/saline, F5/saline, or F10/saline vs saline/saline).

Analysis also showed that all ethanol-treated groups were sensitized at the end of sensitization induction (10th day). Indeed, the locomotor activity of these groups was significantly increased between the first and last days of sensitization induction $(P<0.001$ for all groups except the Mil40/E group: $P=0.002$ ). However, analysis also indicated that the magnitude of sensitization in the Mil40/ethanol, D10/ethanol, and D20/ethanol groups was significantly lower than that of their respective saline/ethanol groups $(P<0.001, P=0.003$, and $P=0.004$, respectively). Milnacipran $40 \mathrm{mg} / \mathrm{kg}$ significantly reduced sensitization and delayed its development compared with the saline/ethanol group, and both doses of desipramine also had the same effect. Conversely, fluoxetine $10 \mathrm{mg} / \mathrm{kg}$ increased locomotor activity compared with the saline/ethanol group on day 9 without any effect on sensitization development. Sensitization of the Mil40/ethanol and D10/ethanol groups was delayed compared with their respective saline/ethanol groups (day $9 v s$ day 3 for the milnacipran experiment and day $6 v s$ day 4 for desipramine).

Phases of induction and expression of sensitization were analyzed separately for each experiment (Figure $7 d-f$ ).
We analyzed the expression phase on day 17 using days 1 and 10 as references. ANOVA showed a significant effect of group $(\mathrm{F}(4,42)=17.779 ; \quad P<0.001)$ and day $(\mathrm{F}(2,84)=64.656 ; P<0.001)$ and a significant interaction $(\mathrm{F}(8,84)=9.111 ; P<0.001)$ in the first experiment (milnacipran, Figure 7d); a significant effect of group $(\mathrm{F}(5,55)=17.015 ; P<0.001)$ and day $(\mathrm{F}(2,110)=136.196$; $P<0.001)$ and a significant interaction $(F(10,110)=6.289$; $P<0.001$ ) in the second experiment (desipramine, Figure 7e); and a significant effect of group $(\mathrm{F}(5,54)=$ 24.326; $P<0.001)$ and day $(\mathrm{F}(2,107)=73.959 ; P<0.001)$ and a significant interaction $(\mathrm{F}(10,107)=18.379 ; P<0.001)$ in the third experiment (fluoxetine, Figure $7 \mathrm{f}$ ). Tukey's post hoc tests showed that locomotor activity in all ethanoltreated groups on day 17 (ethanol challenge) was still significantly higher than on day 1 for each group $(P<0.001$ for all groups) except for the F10/ethanol group $(P=0.057)$. However, when each ethanol-treated group was compared with its own control group on day 17, locomotor activity of both the saline/ethanol and F5/ethanol groups was significantly higher than in their respective control groups (saline/ethanol $v s$ saline/saline: $P<0.001$ in all experiments; F5/ethanol vs F5/saline: $P=0.008$ ). On the other hand, locomotor activity of the Mil10/ethanol, Mil40/ethanol, D10/ethanol, D20/ethanol, and F10/ethanol groups was not different from their respective controls (Mil10/ethanol vs Mil40/saline: $P=0.069$; Mil40/ethanol vs Mil40/saline: $P=0.365$; D10/ethanol vs D10/saline: $P=0.090$; D20/ethanol vs D20/saline: $P=0.179 ; \quad$ F10/ethanol vs F10/saline: $P=0.834$ ). These results showed that the milnacipran-, desipramine-, and fluoxetine-pretreated groups (ie, the Mil10/ethanol, Mil40/ethanol, D10/ethanol, D20/ethanol, and F10/ethanol groups) were no more significantly sensitized on day 17 despite a still increased activity compared with day 1 . Furthermore, these tests revealed a significantly lower locomotor activity on day 17 between the D20/ethanol $(P=0.008)$ or $\mathrm{F} 10 /$ ethanol $(P=0.007)$ groups compared with the saline/ethanol group.

Finally, there were no differences between groups on day 18 (saline solution challenge) in all experiments (two-way RM-ANOVA group $\times$ treatment; ethanol on D17 vs saline on D18), and locomotor activity of all groups was significantly decreased between days 17 and 18, confirming that sensitization was attributable only to ethanol. In summary, a pretreatment with milnacipran $(40 \mathrm{mg} / \mathrm{kg})$ or desipramine (10 or $20 \mathrm{mg} / \mathrm{kg}$ ), but not with fluoxetine, could modulate development of ethanol-induced behavioral sensitization in terms of speed of induction and of magnitude. Moreover, these pretreatments with milnacipran, desipramine, or fluoxetine during the induction phase could decrease or even inhibit the sensitization expression, except at the lowest dose of fluoxetine. Overall, the results showed that the highest doses of both milnacipran and desipramine decreased and delayed sensitization development and blocked its expression. Fluoxetine had no effect on sensitization development, but the highest dose completely blocked its expression.

To assess a possible effect of these inhibitors on ethanol metabolism, we evaluated BECs at day 20, 30 min after an ethanol $2.0 \mathrm{~g} / \mathrm{kg}$ injection in mice that were repeatedly injected with ethanol to induce sensitization. A first oneway ANOVA revealed no differences in BECs $(\mathrm{mg} / \mathrm{dl})$ 


\section{Milnacipran}
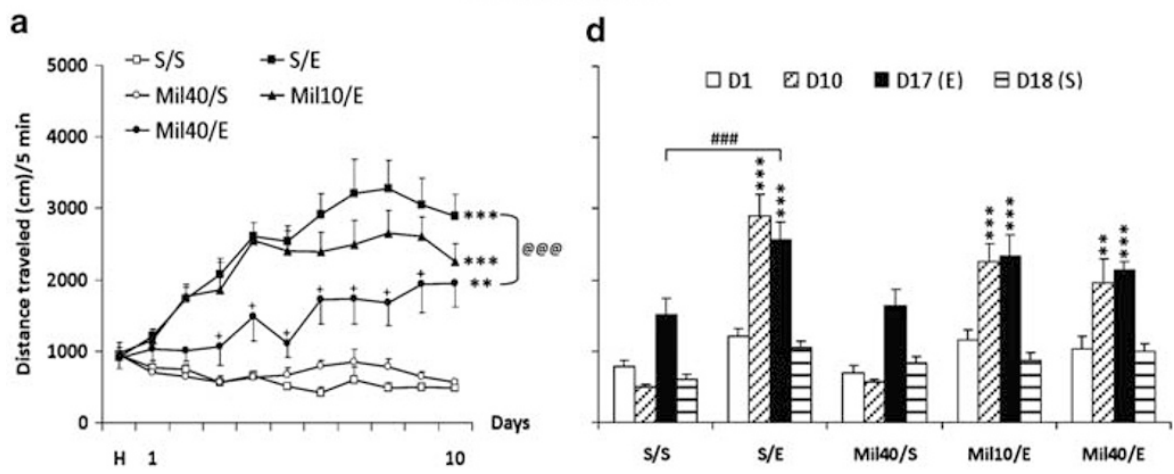

Desipramine
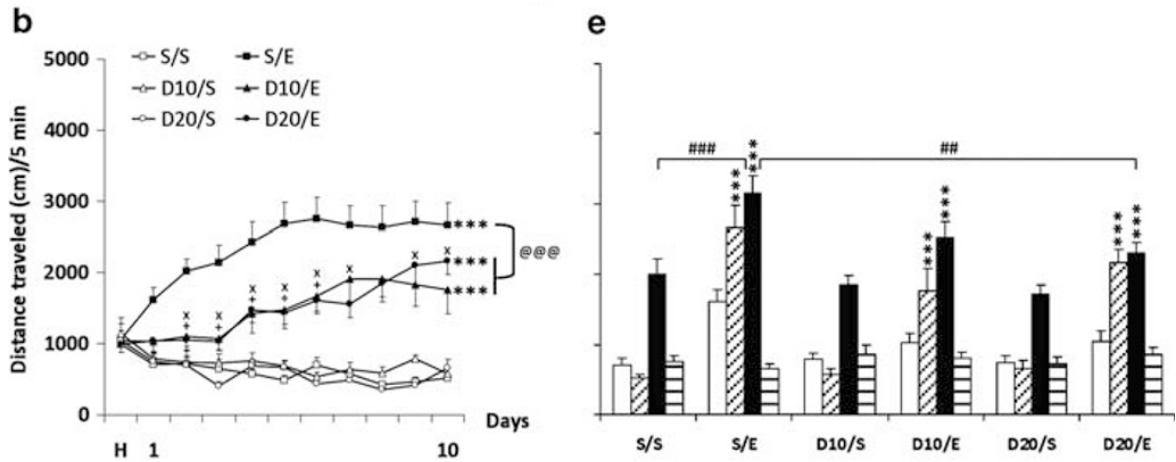

\section{Fluoxetine}
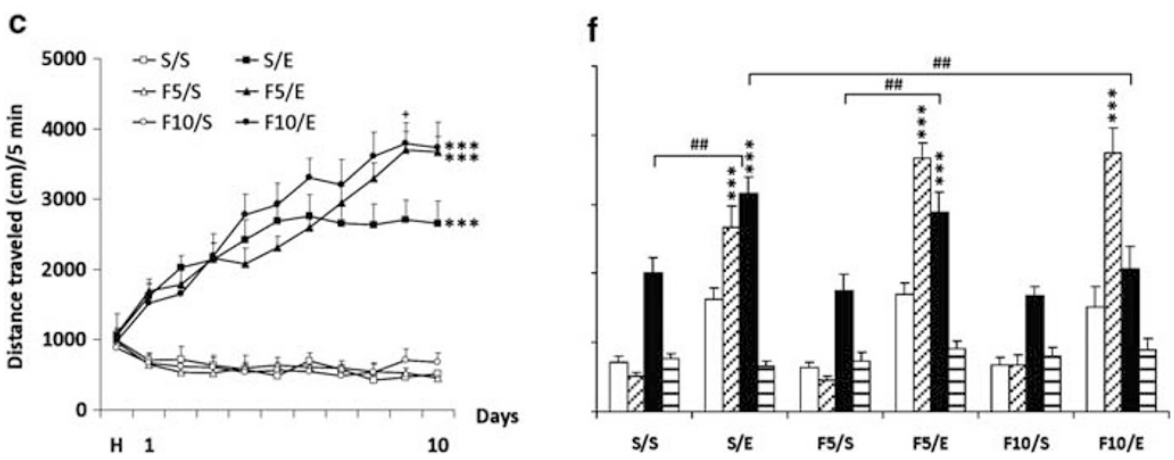

Figure 7 Milnacipran, desipramine, or fluoxetine treatments alter ethanol-induced behavioral sensitization (induction a-c and expression $d-f$ ). Means $( \pm$ SEM) of distance traveled $(\mathrm{cm})$ for a 5 -min test are represented. $(\mathrm{a}-\mathrm{c})$ Induction phase: $\mathrm{On}$ the habituation day $(\mathrm{H})$, each mouse received a saline solution injection. From day I to day 10, all mice ( $n=10$ for all groups except for the Mill0/ethanol, $n=9$, and the Mil40/ethanol, $n=8)$ received an injection of saline solution (S/), milnacipran 10 or $40 \mathrm{mg} / \mathrm{kg}$ (Mil I0/ or $40 /$ ), desipramine 10 or $20 \mathrm{mg} / \mathrm{kg}$ (DI0/ or D20/), or fluoxetine 5 or $10 \mathrm{mg} / \mathrm{kg}$ (F5/ or $\mathrm{FIO} /$ ) before an injection of saline solution (/S) or ethanol $2.0 \mathrm{~g} / \mathrm{kg}(/ \mathrm{E})$. (d-f) Expression phase: on day 17 , all groups of mice received an ethanol (2.0 g/kg) injection, and on day I8, they received a saline injection. On day 18 , the saline injection did not change locomotor activity as compared with day I, thus indicating that the maintenance of ethanol sensitization on day 17 was the result of ethanol and not of a conditioned response to the repeated injection paradigm. $* * P<0.0 \mathrm{I}$ and $* * * P<0.00 \mathrm{I}$ indicate significant increase of locomotor activity compared with day I. ${ }^{+} P<0.05$ indicates a difference of the Mil40/E (a), the D20/E (b), or the FIO/E (c) group compared with its respective S/E group on the same day. ${ }^{\times} P<0.05$ indicates a difference of the DI0/E group compared with the S/E group on the same day. ${ }^{@} P<0.01$ and ${ }^{@ @ @ ~} P<0.001$ indicate a difference between groups throughout the induction phase (from

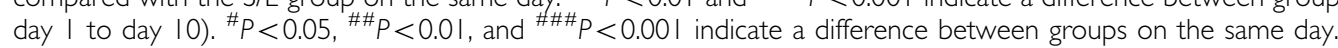

among the saline/saline $(201.3 \pm 4.3 ; n=10)$, saline/ethanol $(204 \pm 3.6 ; n=9)$, and Mil40/ethanol (194.1 $\pm 4.3 ; n=5)$ groups $(\mathrm{F}(2,22)=1.108 ; P=0.349)$. A second one-way ANOVA showed no differences in BECs among the saline/ saline (201.3 $\pm 4.3 ; n=10)$, saline/ethanol (204 $\pm 3.6 ; n=9)$, D10/saline (206.1 $\pm 5.2 ; n=10)$, D10/ethanol (202.5 \pm 4.4 ; $n=10)$, D20/saline $(204 \pm 3.6 ; n=10)$, and the D20/ethanol $(207.6 \pm 2.9 ; \quad n=10)$ groups $(\mathrm{F}(5,53)=0.317 ; \quad P=0.9)$. Finally, a third one-way ANOVA revealed no differences in BECs among the saline/ethanol $(181.48 \pm 2.89 ; n=10)$, F10/saline (183.34 $\pm 3.48 ; \quad n=10), \quad$ and F10/ethanol $(178.64 \pm 2.57 ; n=10)$ groups $(\mathrm{F}(2,27)=0.620 ; P=0.546)$.

\section{Effect of a Single Administration of Milnacipran on the} Expression of Ethanol-Induced Locomotor Sensitization

When milnacipran was injected only during the expression phase, it had no effect on locomotor response induced by 
ethanol in sensitized mice (data not shown). In this test, the expression phase was analyzed on days 30 and 31 (ie, 11 and 12 days after the challenge) in mice from the saline/ethanol group $(n=10)$. Increased locomotor activity was observed on day 30 , indicating that mice were still sensitized. The day after, milnacipran injected before ethanol had no effect, revealing a lack of effect of milnacipran once mice were sensitized.

\section{DISCUSSION}

Our results provide evidence that 5-HTT and NET inhibitors and also the dual antidepressant milnacipran block ethanol self-administration in both dependent and non-dependent rats. Milnacipran reduced excessive ethanol consumption and prevented relapse after protracted abstinence in alcohol-dependent rats at a dose that was ineffective in non-dependent animals and on sucrose selfadministration. This effect likely involves both 5-HT and NE signaling because both 5-HTT and NET inhibitors completely block excessive ethanol consumption during short-term withdrawal and their effectiveness is higher than that of milnacipran. Of interest, milnacipran was more effective in dependent animals compared with non-dependent ones. Milnacipran also blocked ethanol reward and thus inhibited the acquisition of ethanol-induced CPP. Finally, milnacipran reduced the magnitude of ethanolinduced locomotor sensitization and delayed its induction, as clearly observed with the NET inhibitor.

The level of responding from the dependent group of animals is similar to that described in other studies (Gehlert et al, 2007; O'Dell et al, 2004; Roberts et al, 2000). Milnacipran reduced excessive alcohol self-administration in alcohol-dependent rats at doses that were ineffective in non-dependent rats and on sucrose intake. This effect may result from an inhibitory influence on 5-HTT and NET because both desipramine and fluoxetine completely blocked alcohol self-administration. Desipramine and fluoxetine were also much more potent than milnacipran in reducing ethanol self-administration because these treatments completely blocked self-administration and their effects were still present 1 day after treatment. Of note, at $10 \mathrm{mg} / \mathrm{kg}$, milnacipran reduced alcohol self-administration only in dependent animals, whereas both desipramine and fluoxetine completely blocked this behavior in the dependent and non-dependent groups. Milnacipran significantly decreased sucrose self-administration at the $20 \mathrm{mg} / \mathrm{kg}$ dose, but not at the $10 \mathrm{mg} / \mathrm{kg}$ dose, although this latter dose was effective on ethanol self-administration. These data suggest that milnacipran affects general rewarding and motivational mechanisms, as already reported for naltrexone (Stromberg et al, 2002). Nevertheless, milnacipran reduced ethanol selfadministration at a lower dose with a significant effect at $10 \mathrm{mg} / \mathrm{kg}$ in ethanol-dependent rats, suggesting that this low dose was more selective on ethanol self-administration. The fact that milnacipran had a greater effect on alcohol selfadministration in alcohol-dependent rats suggests that chronic intermittent alcohol exposure may induce changes in both 5-HT and NE systems, rendering the rats more sensitive to milnacipran. This idea remains to be further investigated, but it is interesting to note that dependent animals were also more sensitive to desipramine or fluoxetine, as a partial recovery was observed in these animals compared with non-dependent rats. A modification of metabolism of these molecules in alcohol-dependent animals cannot be ruled out. In contrast, both nondependent and dependent animals exhibited a recovery the day after milnacipran treatment that may be attributable to its short half-life compared with fluoxetine and desipramine (Boyer and Briley, 1998). Milnacipran could be effective in treating alcohol-dependent subjects at doses that are inert in healthy subjects. Of interest, chronic ingestion of ethanol and ethanol withdrawal induce changes in both NE and 5-HT sensitivity in rat cerebral cortex (French et al, 1975; French et al, 1977). A clinical study has shown that plasma NE levels are significantly elevated in early withdrawal and decline from early to late withdrawal (Patkar et al, 2003). Those authors also showed that 5-HT levels declined throughout the 2 -week withdrawal period. These disturbances could explain the increased sensitivity of dependent animals to milnacipran compared with non-dependent animals. Because acute alcohol exposure is known to increase both 5-HT and NE turnover and release, alcohol self-administration may be an attempt to compensate for the deficit in both 5-HT and NE, and milnacipran could substitute for the effect of alcohol and thus decrease alcohol self-administration. The mechanism by which milnacipran modulates ethanol self-administration remains to be elucidated and could be related to anxiety. Mochizuki et al (2002) reported that acute treatment with milnacipran exerts antidepressant and anxiolytic effects in rats. The efficacy of milnacipran in reducing alcohol reward during acute withdrawal may be attributable to its anxiolytic effects as it is well established that anxiety induced by ethanol withdrawal is an important factor in the negative reinforcement leading to excessive alcohol drinking (Schuckit and Hesselbrock, 1994). Of note, we showed that when milnacipran was administered after a prolonged period of abstinence ( 3 weeks), it completely blocked alcohol- plus cue-induced relapse in both groups at the highest dose. Importantly, milnacipran at the lowest dose was effective only in dependent animals. Thus, the efficacy of milnacipran observed in alcohol-dependent rats may be the result of an effect on alcohol withdrawal-induced anxiety during both acute and chronic withdrawal. Our results suggest that milnacipran could reduce negative reinforcement. To test its effect on positive reinforcement, we carried out other experiments such as CPP and behavioral sensitization in non-dependent animals. Few studies have suggested a potential role for SNRIs in the treatment of addiction. The SNRI venlafaxine has been shown to reduce acquisition of intravenous heroin self-administration in rats (Magalas et al, 2005), and duloxetine dose-dependently suppressed two-bottle choice alcohol binge drinking and operant alcohol responding ( $\mathrm{Ji}$ et al, 2008), indicating that SNRI may be useful in reducing the abuse of such substances. Our results showed that fluoxetine is very effective in decreasing ethanol self-administration. Other studies have already demonstrated that selective $5-\mathrm{HT}$ reuptake inhibitors (SSRIs) diminish alcohol self-administration in rats (Lê et al, 1996; Wilson et al, 1998). For example, fluoxetine reduced ethanol self-administration in non-dependent animals (Lê et al, 1999; Maurel et al, 1999) and reduced 
responding on a lever leading to presentation of an ethanolpaired conditioned stimulus in rat (Wilson et al, 2000). Of interest, Wilson et al (2000) also showed that this conditioned reinforcing property of ethanol could be reduced by the 5-HT releaser $\mathrm{D}$-fenfluramine and the activation of $5-\mathrm{HT}_{1 \mathrm{~A}}$ and $5-\mathrm{HT}_{1 \mathrm{~B}}$ receptors. SSRIs also have been reported to decrease relapse to alcohol in humans (Naranjo and Sellers, 1989; Sellers et al, 1992), but this finding was not confirmed in another study (Zernig et al, 1997). The present data also show that desipramine potently inhibited ethanol self-administration during acute withdrawal. The mechanism by which NET inhibition is effective against ethanol reinforcement remains to be determined, but the involvement of $\alpha 2$-receptors is a possibility as an $\alpha 2$ agonist reduces ethanol self-administration (Lê et al, 2005); however, both $\alpha 1$ - and $\beta$-receptor antagonists attenuate ethanol self-administration in alcohol-dependent rats (Gilpin and Koob, 2010; Walker et al, 2008). To our knowledge, no study has addressed the effect of a selective NET inhibitor on ethanol self-administration. Nonetheless, reboxetine can attenuate both intravenous nicotine and sucrose self-administration in rats (Rauhut et al, 2002). Note that NE may enhance ethanol sensitivity, reducing the amount of ethanol necessary for reward (Haughey et al, 2006).

In alcohol-naive rats, milnacipran $(40 \mathrm{mg} / \mathrm{kg}$ ) blocked the rewarding properties of ethanol in the CPP paradigm. A previous study showed that enhancing $5-\mathrm{HT}$ transmission with fluoxetine did not influence ethanol reward in the same paradigm (Risinger, 1997). Another study found that prefrontal NE transmission was critical in alcohol-induced CPP in mice (Ventura et al, 2006). The SNRI venlafaxine attenuates morphine-induced reinstatement in a CPP paradigm (Lu et al, 2001). Altogether, these results indicate that the SNRI-induced decrease in the rewarding properties of alcohol and other drugs of abuse could be the result of their NE transmission-enhancing properties. In addition, $24 \mathrm{~h}$ after injection of 5-HTT or NET inhibitors, alcohol consumption was reduced in alcohol-preferring rats (Murphy et al, 1985).

The phenomenon of behavioral sensitization has been suggested to be a key component of drug addiction (Robinson and Berridge, 1993). Previous studies have shown that naltrexone and acamprosate, two clinically used anti-craving compounds, block ethanol-induced sensitization in mice (Chester et al, 2001; Pastor and Aragon, 2006). In our study, behavioral sensitization was quite robust and long lasting; this phenomenon was still present until day 44 (data not shown). The sensitized response to acute ethanol $(2.0 \mathrm{~g} / \mathrm{kg})$ was also evident when mice were tested following a 7-day abstinence period, suggesting persistent neural changes induced by ethanol, as previously reported (Lessov and Phillips, 1998). Ethanol-induced behavioral sensitization was delayed and dose dependently reduced by milnacipran. Its effect was observed throughout sensitization development, indicating that it counteracts the neural sensitization leading to drug dependence. This latter point is supported by the fact that milnacipran injected during the induction phase reduced sensitization expression at day 17, ie, 7 days after the last milnacipran administration and in a dose-dependent manner. In general, our data support the concept that the effect of milnacipran on sensitization development involves mainly the NE component, whereas its effect on expression involves both 5-HT and NE systems. In addition, when mice injected only once are sensitized (ie, during the expression phase), acute milnacipran $(40 \mathrm{mg} / \mathrm{kg}$ ) had no effect on the locomotor response to ethanol (data not shown). Thus, the pharmacological blockade of locomotor sensitization by milnacipran seems to occur only during the induction phase when ethanol-induced neuro-adaptations are not yet established. Our results demonstrate that desipramine reduces and delays sensitization development and also reduces ethanol response during expression phase. To our knowledge, our study is the first to investigate the effect of a NET inhibitor on ethanol-induced sensitization. A previous study reported that desipramine $(30 \mathrm{mg} / \mathrm{kg})$, but not fluoxetine, potentiates the acute hypnotic/sedative effect of ethanol $(3.0 \mathrm{~g} / \mathrm{kg})$ in mice and that this effect may be mediated via $\alpha 2$-adrenoreceptor (Boyce-Rustay et al, 2008). We provide evidence that fluoxetine has opposite effects depending on sensitization phases. It enhances the locomotor response to ethanol at the end of the induction phase, whereas it reduces response to ethanol during the expression phase. Our results are in line with those of Goeldner et al (2005) showing a facilitation of ethanol-induced behavioral sensitization by fluoxetine $10 \mathrm{mg} / \mathrm{kg}$. Other studies have found that $5-\mathrm{HT}$ transmission is involved in ethanol-induced sensitization; $5-\mathrm{HT}_{3}$ and 5- $\mathrm{HT}_{2 \mathrm{C}}$ antagonists blocked sensitization (Ferraz and Boerngen-Lacerda, 2008; Umathe et al, 2009), whereas a $5-\mathrm{HT}_{1 \mathrm{~A}}$ receptor antagonist did not influence ethanolinduced locomotor sensitization (Risinger and Boyce, 2002). Both 5-HT and NE have been proposed to have a major role in addiction (Weinshenker and Schroeder, 2007; Wilson et al, 2000). Our data support the hypothesis that increasing both 5-HT and NE transmissions could be a promising target for treating alcohol addiction. Even though the precise nature of the brain pathways or mechanisms that are involved requires additional investigation, a few hypotheses can be formulated to explain these mechanisms. In animals, sensitized locomotor behavior is initiated in the ventral tegmental area (VTA) and is then expressed in the nucleus accumbens (Kalivas and Duffy, 1990), presumably through enhancement of dopamine responses that are influenced by different neurotransmitters such as dopamine (Palmer et al, 2003) and 5-HT (Goeldner et al, 2005). Both rewarding and locomotor stimulating effects of alcohol involve neuro-adaptations in the mesocorticolimbic dopaminergic system. The 5-HT seems to inhibit this reward system; for example, firing of VTA dopaminergic neurons is inhibited following SSRI treatment (Di Mascio et al, 1998). Both the raphe nuclei (5-HT) and locus coeruleus (NE) project to the VTA and inhibit VTA dopaminergic neurons via $5-\mathrm{HT}_{1 \mathrm{~B} / 1 \mathrm{C}}$ and/or 5- $\mathrm{HT}_{2 \mathrm{~B} / 2 \mathrm{C}}$ receptors (Prisco and Esposito, 1995) and adrenergic $\alpha 1$ receptors, respectively. Therefore, by elevating extracellular levels of 5-HT and NE, milnacipran may enhance the inhibitory influence of these neurotransmitters on dopaminergic neurons and consequently counteract or attenuate the effect of alcohol. The fact that milnacipran could counteract the alcohol-induced increase in dopamine levels in the nucleus accumbens may explain, at least in part, its efficacy in reducing both the rewarding and locomotor stimulating effects of alcohol. Milnacipran may also disturb the 5-HT-NE uncoupling, a 
hypothesis that has been proposed in sensitization to drugs of abuse (Lanteri et al, 2008). The mutual regulation of NE and 5-HT neurons is impaired by repeated treatments with ethanol, and this effect may involve both $\alpha 1 b$-adrenergic and $5-\mathrm{HT}_{2 \mathrm{~A}}$ receptors (Lanteri et al, 2008). Milnacipran could help in resynchronized activations of each transmission system.

In conclusion, our data demonstrated that inhibitors of 5-HT or NE uptake are highly effective in reducing ethanol self-administration in dependent and non-dependent rats. The dual antidepressant milnacipran dose-dependently reduced ethanol self-administration in dependent animals. It also reduced both alcohol self-administration and relapse in non-dependent and alcohol-dependent animals but was effective at a lower dose in dependent animals and at a dose that was ineffective on sucrose self-administration. Milnacipran prevented ethanol-induced place preference and reduced ethanol-induced sensitization. Its effect on ethanolinduced sensitization may be mainly mediated via $\mathrm{NE}$ transmission because sensitization development was blocked by desipramine, whereas fluoxetine facilitated sensitization. Our results suggest that the use of inhibitors of both 5-HT and NE uptake might be an effective strategy in alcoholism treatment.

\section{ACKNOWLEDGEMENTS}

This study was supported by the Regional Council of Picardie (RCP), INSERM, MiLDT/Inca/INSERM, Institut de France/Fondation NRJ, and IREB. ES and HH are supported by doctoral fellowships from the RCP; RL is supported by a doctoral fellowship from MENRT. SA is supported by a post-doctoral fellowship from the RCP. We thank Dr Lucilla Mansuy from the Pierre Fabre for critical revision of the manuscript and Ludovic Didier for his technical assistance.

\section{DISCLOSURE}

This research was supported in part by Pierre Fabre funding. E André is an employee of Pierre Fabre. The remaining authors have no competing financial interest.

\section{REFERENCES}

Barbier E, Pierrefiche O, Vaudry D, Vaudry H, Daoust M, Naassila M (2008). Long-term alterations in vulnerability to addiction to drugs of abuse and in brain gene expression after early life ethanol exposure. Neuropharmacology 55: 1199-1211.

Boyce-Rustay JM, Palachick B, Hefner K, Chen YC, Karlsson RM, Millstein RA et al (2008). Desipramine potentiation of the acute depressant effects of ethanol: modulation by alpha2-adrenoreceptors and stress. Neuropharmacology 55: 803-811.

Boyer P, Briley M (1998). Milnacipran, a new specific serotonin and noradrenaline reuptake inhibitor. Drugs Today (Barc) 34: 709-720.

Carnicella S, Ahmadiantehrani S, He D, Nielsen CK, Bartlett SE, Janak PH et al (2009). Cabergoline decreases alcohol drinking and seeking behaviors via glial cell line-derived neurotrophic factor. Biol psychiatry 66: 146-153.

Chester JA, Grahame NJ, Li TK, Lumeng L, Froehlich JC (2001). Effects of acamprosate on sensitization to the locomotorstimulant effects of alcohol in mice selectively bred for high and low alcohol preference. Behav Pharmacol 12: 535-543.
Daoust M, Saligaut C, Chadelaud M, Chretien P, Moore N, Boismare F (1984). Attenuation by antidepressant drugs of alcohol intake in rats. Alcohol 1: 379-383.

Didone V, Quoilin C, Tirelli E, Quertemont E (2008). Parametric analysis of the development and expression of ethanol-induced behavioral sensitization in female Swiss mice: effects of dose, injection schedule, and test context. Psychopharmacology (Berl) 201: 249-260.

Di Mascio M, Di Giovanni G, Di Matteo V, Prisco S, Esposito E (1998). Selective serotonin reuptake inhibitors reduce the spontaneous activity of dopaminergic neurons in the ventral tegmental area. Brain Res Bull 46: 547-554.

Ferraz IC, Boerngen-Lacerda R (2008). Serotonin 5-HT2 receptor antagonist does not reverse established ethanol-induced sensitization but blocks its development and expression. Pharmacol Biochem Behav 88: 456-464.

Forgie ML, Stewart J (1994). Effect of prepuberal ovariectomy on amphetamine-induced locomotor activity in adult female rats. Horm Behav 28: 241-260.

French SW, Palmer DS, Narod ME (1975). Effect of withdrawal from chronic ethanol ingestion on the cAMP response of cerebral cortical slices using the agonists histamine, serotonin, and other neurotransmitters. Can J Physiol Pharmacol 53: 248-255.

French SW, Palmer DS, Wiggers KD (1977). Changes in receptor sensitivity of the cerebral cortex and liver during chronic ethanol ingestion and withdrawal. Adv Exp Med Biol 85A: 515-538.

Gilpin NW, Richardson HN, Cole M, Koob GF (2008). Vapor inhalation of alcohol in rats. Curr Protoc Neurosci. Chapter 9, unit 9.29.

Gilpin NW, Koob GF (2010). Effects of $\beta$-adrenoceptor antagonists on alcohol drinking by alcohol-dependent rats. Psychopharmacology (Berl) 212: 431-439.

Gehlert DR, Cippitelli A, Thorsell A, Lê AD, Hipskind PA, Hamdouchi C et al (2007). 3-(4-Chloro-2-morpholin-4-ylthiazol-5-yl)-8-(1-ethylpropyl)-2,6-dimethyl-imidazo[1,2-b]pyridazine: a novel brain-penetrant, orally available corticotropinreleasing factor receptor 1 antagonist with efficacy in animal models of alcoholism. J Neurosci 27: 2718-2726.

Goeldner FO, Pigatto G, Ribeiro AF, Machado HB, BoerngenLacerda R (2005). Influence of fluoxetine and paroxetine in behavioral sensitization induced by ethanol in mice. Pharmacol Biochem Behav 82: 388-396.

Haughey HM, Kaiser AL, Johnson TE, Bennett B, Sikela JM, Zahniser NR (2006). Norepinephrine transporter: a candidate gene for initial ethanol sensitivity in inbred long-sleep and short-sleep mice. Alcohol Clin Exp Res 29: 1759-1768.

Heinz A, Ragan P, Jones DW, Hommer D, Williams W, Knable MB et al (1998). Reduced central serotonin transporters in alcoholism. Am J Psychiatry 155: 1544-1549.

Hwang BH, Wang GM, Wong DT, Lumeng L, Li TK (2000). Norepinephrine uptake sites in the locus coeruleus of rat lines selectively bred for high and low alcohol preference: a quantitative autoradiographic binding study using [3H]-tomoxetine. Alcohol Clin Exp Res 24: 588-594.

Ji D, Gilpin NW, Richardson HN, Rivier CL, Koob GF (2008). Effects of naltrexone, duloxetine, and a corticotropin-releasing factor type 1 receptor antagonist on binge-like alcohol drinking in rats. Behav Pharmacol 19: 1-12.

Kalivas PW, Duffy P (1990). Effect of acute and daily cocaine treatment on extracellular dopamine in the nucleus accumbens. Synapse 5: 48-58.

Kalivas PW, Stewart J (1991). Dopamine transmission in the initiation and expression of drug- and stress-induced sensitization of motor activity. Brain Res Rev 16: 223-244.

Kenna GA (2010). Medications acting on the serotonergic system for the treatment of alcohol dependent patients. Curr Pharm Des 16: $2126-2135$. 
Lanteri C, Salomon L, Torrens Y, Glowinski J, Tassin JP (2008). Drugs of abuse specifically sensitize noradrenergic and serotonergic neurons via a non-dopaminergic mechanism. Neuropsychopharmacology 33: 1724-1734.

Lê AD, Harding S, Juzytsch W, Funk D, Shaham Y (2005). Role of alpha-2 adrenoceptors in stress-induced reinstatement of alcohol seeking and alcohol self-administration in rats. Psychopharmacology (Berl) 179: 366-373.

Lê AD, Poulos CX, Harding S, Watchus J, Juzytsch W, Shaham Y (1999). Effects of naltrexone and fluoxetine on alcohol selfadministration and reinstatement of alcohol seeking induced by priming injections of alcohol and exposure to stress. Neuropsychopharmacology 21: 435-444.

Lê AD, Tomkins DM, Sellers EM (1996). Uses of serotonin and opiate based drugs in the pharmacotherapy of alcohol dependence: an overview of the preclinical data. Alcohol Alcohol 31: $27-32$.

LeMarquand D, Pihl RO, Benkelfat C (1994). Serotonin and alcohol intake, abuse, and dependence: findings of animal studies. Biol Psychiatry 36: 395-421.

Lessov CN, Phillips TJ (1998). Duration of sensitization to the locomotor stimulant effects of ethanol in mice. Psychopharmacology 135: 374-382.

Liappas J, Paparrigopoulos T, Tzavellas E, Rabavilas A (2005). Mirtazapine and venlafaxine in the management of collateral psychopathology during alcohol detoxification. Prog Neuropsychopharmacol Biol Psychiatry 29: 55-60.

Lu L, Su WJ, Yue W, Ge X, Su F, Pei G et al (2001). Attenuation of morphine dependence and withdrawal in rats by venlafaxine, a serotonin and noradrenaline reuptake inhibitor. Life Sci 69: $37-46$.

Magalas Z, De Vry J, Tzschentke TM (2005). The serotonin/ noradrenaline reuptake inhibitor venlafaxine attenuates acquisition, but not maintenance, of intravenous self-administration of heroin in rats. Eur J Pharmacol 528: 103-109.

Markou A, Kosten TR, Koob GF (1998). Neurobiological similarities in depression and drug dependence: a self-medication hypothesis. Neuropsychopharmacology 18: 135-174.

Maurel S, De Vry J, Schreiber R (1999). 5-HT receptor ligands differentially affect operant oral self-administration of ethanol in the rat. Eur J Pharmacol 370: 217-223.

McMillen BA, Shank JE, Jordan KB, Williams HL, Basile AS (2007). Effect of DOV 102,677 on the volitional consumption of ethanol by Myers' high ethanol-preferring rat. Alcohol Clin Exp Res 31: 1866-1871.

Mochizuki D, Tsujita R, Yamada S, Kawasaki K, Otsuka Y, Hashimoto S et al (2002). Neurochemical and behavioural characterization of milnacipran, a serotonin and noradrenaline reuptake inhibitor in rats. Psychopharmacology (Berl) 162: 323-332.

Murphy JM, Waller MB, Gatto GJ, McBride WJ, Lumeng L, Li TK (1985). Monoamine uptake inhibitors attenuate ethanol intake in alcohol-preferring (P) rats. Alcohol 2: 349-352.

Naassila M, Beaugé FJ, Sébire N, Daoust M (2000). Intracerebroventricular injection of antisense oligos to nNOS decreases rat ethanol intake. Pharmacol Biochem Behav 67: 629-636.

Naranjo CA, Sellers EM (1989). Serotonin uptake inhibitors attenuate ethanol intake in problem drinkers. Recent Dev Alcohol 7: 255-266.

O'Dell LE, Roberts AJ, Smith RT, Koob GF (2004). Enhanced alcohol self-administration after intermittent $v s$ continuous alcohol vapor exposure. Alcohol Clin Exp Res 28: 1676-1682.

Owen RT (2008). Milnacipran hydrochloride: its efficacy, safety and tolerability profile in fibromyalgia syndrome. Drugs Today (Barc) 44: 653-660.

Palmer AA, Low MJ, Grandy DK, Phillips TJ (2003). Effects of a Drd2 deletion mutation on ethanol-induced locomotor stimulation and sensitization suggest a role for epistasis. Behav Genet 33: $311-324$
Pastor R, Aragon CM (2006). The role of opioid receptor subtypes in the development of behavioral sensitization to ethanol. Neuropsychopharmacology 31: 1489-1499.

Patkar AA, Gopalakrishnan R, Naik PC, Murray HW, Vergare MJ, Marsden CA (2003). Changes in plasma noradrenaline and serotonin levels and craving during alcohol withdrawal. Alcohol Alcohol 38: 224-231.

Peana AT, Muggironi G, Calvisi G, Enrici P, Mereu M, Nieddu M et al (2009). L-cysteine reduces oral ethanol self-administration and reinstatement of ethanol-drinking behavior in rats. Pharmacol Biochem Behav 94: 431-437.

Pettinati HM (2001). The use of selective serotonin reuptake inhibitors in treating alcoholic subtypes. J Clin Psychiatry 62: 26-31.

Phillips TJ, Huson M, Gwiazdon C, Burkhart-Kasch S, Shen EH (1995). Effects of acute and repeated ethanol exposures on the locomotor activity of BXD recombinant inbred mice. Alcohol Clin Exp Res 19: 269-278.

Prisco S, Esposito E (1995). Differential effects of acute and chronic fluoxetine administration on the spontaneous activity of dopaminergic neurones in the ventral tegmental area. $\mathrm{Br} J$ Pharmacol 116: 1923-1931.

Rauhut AS, Mullins SN, Dwoskin LP, Bardo MT (2002). Reboxetine: attenuation of intravenous nicotine self-administration in rats. J Pharmacol Exp Ther 303: 664-672.

Rimondini R, Arlinde C, Sommer W, Heilig M (2002). Long-lasting increase in voluntary ethanol consumption and transcriptional regulation in the rat brain after intermittent exposure to alcohol. FASEB 16: 27-35.

Risinger FO (1997). Fluoxetine's effects on ethanol's rewarding, aversive and stimulus properties. Life Sci 61: 235-242.

Risinger FO, Boyce JM (2002). 5-HT1A receptor blockade and the motivational profile of ethanol. Life Sci 71: 707-715.

Roberts AJ, Heyser CJ, Cole M, Griffin P, Koob GF (2000). Excessive ethanol drinking following a history of dependence: animal model of allostasis. Neuropsychopharmacology 22: 581-594.

Robinson TE (1984). Behavioural sensitization: characterization of enduring changes in rotational behavior produced by intermittent injections of amphetamine in male and female rats. Psychopharmacology (Berl) 84: 466-475.

Robinson TE, Berridge KC (1993). The neural basis of drug craving: an incentive sensitization theory of addiction. Brain Res Rev 18: 247-291.

Samson HH (1986). Initiation of ethanol reinforcement using a sucrose-substitution procedure in food- and water-sated rats. Alcohol Clin Exp Res 10: 436-442.

Schuckit MA, Hesselbrock V (1994). Alcohol dependence and anxiety disorders: what is the relationship? Am J Psychiatry 151: 1723-1734.

Sellers EM, Higgins GA, Sobell MB (1992). 5-HT and alcohol abuse. Trends Pharmacol Sci 13: 69-75.

Stromberg MF, Rukstalis MR, Mackler SA, Volpicelli JR, O’Brien CP (2002). A comparison of the effects of 6-beta naltrexol and naltrexone on the consumption of ethanol or sucrose using a limitedaccess procedure in rats. Pharmacol Biochem Behav 72: 483-490.

Tachibana K, Matsumoto M, Togashi H, Kojima T, Morimoto Y, Kemmostu O et al (2004). Milnacipran, a serotonin and noradrenaline reuptake inhibitor, suppresses long-term potentiation in the rat hippocampal CA1 field via 5-HT1A receptors and alpha 1-adrenoceptors. Neurosci Lett 357: 91-94.

Tanda G, Frau R, Di Chiara G (1996). Chronic desipramine and fluoxetine differentially affect extracellular dopamine in the rat prefrontal cortex. Psychopharmacology 127: 83-87.

Umathe SN, Bhutada PS, Raut VS, Jain NS, Mundhada YR (2009). The 5-HT3 receptor antagonist, ondansetron, blocks the development and expression of ethanol-induced locomotor sensitization in mice. Behav Pharmacol 20: 78-83. 
Valdez GR, Roberts AJ, Chan K, Davis H, Brennan M, Zorrilla EP et al (2002). Increased ethanol self-administration and anxietylike behavior during acute ethanol withdrawal and protracted abstinence: regulation by corticotropin-releasing factor. Alcohol Clin Exp Res 26: 1494-1501.

Ventura R, De Carolis D, Alcaro A, Puglisi-Allegra S (2006). Ethanol consumption and reward depend on norepinephrine in the prefrontal cortex. Neuroreport 17: 1813-1817.

Walker BM, Rasmussen DD, Raskind MA, Koob GF (2008). alpha1-noradrenergic receptor antagonism blocks dependenceinduced increases in responding for ethanol. Alcohol 42: 91-97.

Weinshenker D, Schroeder JP (2007). There and back again: a tale of norepinephrine and drug addiction. Neuropsychopharmacology 32: 1433-1451.
Wilson AW, Costall B, Neill JC (2000). Manipulation of operant responding for an ethanol-paired conditioned stimulus in the rat by pharmacological alteration of the serotonergic system. J Psychopharmacol 14: 340-346.

Wilson AW, Neill JC, Costall B (1998). An investigation into the effects of 5-HT agonists and receptor antagonists on ethanol selfadministration in the rat. Alcohol 16: 249-270.

Yoon SJ, Pae CU, Kim DJ, Namkoong K, Lee E, Oh DY et al (2006). Mirtazapine for patients with alcohol dependence and comorbid depressive disorders: a multicentre, open label study. Prog Neuropsychopharmacol Biol Psychiatry 30: 1196-1201.

Zernig G, Fabisch K, Fabisch H (1997). Pharmacotherapy for alcohol dependence. Trends Pharmacol Sci 18: 229-231. 